\title{
Uma "experiência" filosófica no GAN
}

\author{
Fábio Faria Gachet; \\ Fernanda Rocha Gay; \\ Marlene A. C. Antinoro e \\ Viviane Horta
}

(...) Digamos agora por respeito à verdade, que o seu pensar não foi assim tão claro, o pensamento, afinal de contas, já por outros, ou o mesmo, foi dito, é como um grosso novelo de fio enrolado sobre si mesmo, frouxo nuns pontos, noutros apertados até à sufocação $e$ ao estrangulamento, está aqui dentro da cabeça, mas é impossivel conhecer-lhe a extensão toda, seria preciso desenrolá-lo, estendê-lo, $e$ finalmente medi-lo, mas isto, por mais que se intente, ou finja intentar, parece que não o pode fazer o próprio sem ajudas, alguém tem de vir um dia dizer por onde se deve cortar o cordão que liga o homem ao seu umbigo, atar o pensamento à sua causa.

\author{
José Saramago - O Evangelho Segundo \\ Jesus Cristo
}

Um pouco da nossa história no projeto...

Participar, neste ano, de um projeto que se iniciou em 1998 e que, parece-nos, nunca se apresentar do mesmo jeito, permitiu-nos caminhar em busca de uma filosofia. Uma caminhada que fizemos no caminhando e constituída de passos que não desejávamos seguros. Queríamos o direito de cair e levantar já não sendo os mesmos e as mesmas.

Logo no início falávamos sobre a experiência ou o correr riscos... E as questões eram: Como possibilitar experiências que permitam riscos numa instituição escolar? Como possibilitar o pensamento filosófico e acontecimentos? Como prescindir de regras preestabelecidas na organização de atividades em um grupo onde, professores e alunos não tinham funções de ensinar ou aprender? Ensejávamos todos aprendizes... 
Apesar do entusiasmo, a idéia não era de reverência ao pensamento filosófico ou ao projeto. Ao contrário, a idéia era de vivenciá-los e experimentá-los não nos colocando em um limbo, mas no turbilhão de vozes - onde falamos e ouvimos.

\section{Colocar-se à mostra tem seus riscos}

Assim iniciou-se este trabalho. Muitas expectativas. Tudo era muito novo. Imprevisível. A idéia de correr riscos fazia-se presente desde os primeiros encontros. Seis pessoas com visões diversas, palavras diversas, sentires, quereres e pensares diversos, contudo, imbuídas de um sentimento comum: dar início ao Projeto de Filosofia na Escola, no Centro de Ensino Fundamental - GAN, da SEDF, numa turma de $8^{\mathrm{a}}$ série, turno matutino.

O desafio foi grande e, ao mesmo tempo, instigante. Alguns de nós nunca havíamos trabalhado com uma turma de adolescentes. Como seria?

Nossas reuniões para a preparação das oficinas eram sempre permeadas por novidades e inquietações. Cada um trazia uma idéia, uma possibilidade de discussão com os alunos. Tudo era muito conversado, exemplificado às vezes, até conseguirmos fechar um tema para o encontro ou ainda preparar o tema proposto pelos alunos.

Desta maneira, havia sempre muita expectativa nas reuniões que antecediam as oficinas e também no momento da sua realização. Com isso, nos preparávamos para perceber $e$, principalmente, entender qual o movimento da turma durante os encontros. Assim, o ritmo que deu formato ao grupo, começava a se definir. Podíamos, assim, analisar constantemente o nosso trabalho, a escolha dos temas e a resposta dos alunos a esses temas.

Sabíamos que ao desenvolver este trabalho com os adolescentes, estaríamos correndo riscos, assim como em toda a experiência. E nos perguntávamos algumas vezes: De que maneira levar a idéia da filosofia àquele grupo? Será que realmente era essa a proposta do projeto? Se for, em quais momentos estávamos filosofando nos encontros? Corríamos realmente muitos riscos. A maioria imprevisíveis. Não havia nenhuma fórmula 
a ser seguida, nenhum conteúdo previamente elaborado para que o colocássemos em prática. Restava-nos, então, trabalhar com a experiência de cada encontro, de cada acontecimento.

Talvez seja esta a proposta dessas oficinas de filosofia: buscar em cada discussão, em cada novo encontro a possibilidade de rompimento com algumas estruturas bastante sedimentadas, ora por nós professores, ora pela própria instituição de ensino. Cabe a nós perceber se o projeto, com o formato que hoje ele tem, vem propiciando um espaço onde possamos nos envolver com textos, leituras, discussões e práticas.

\section{Caráter "experencial" do Projeto}

É interessante sempre ressaltar o caráter experimental do Projeto de Filosofia na Escola, ou seja, a sua busca em trabalhar a filosofia com crianças e jovens como uma proposta educacional e social, mas com tentativas de possibilitar o novo no campo do ensino fundamental e médio. A prática pedagógica deve estar sempre na berlinda, sob constante questionamento e avaliação, sem métodos ou programas a serem cumpridos a priori. Prática resultante de encontros não lineares e não hierárquicos e que no movimento geram acontecimentos. Acontecimentos que propiciam experiência.

Para tanto, era necessário aprender com a experiência. Foucault, em sua entrevista "Como nasce un libro experiencia" (1996), nos diz que a experiência é algo que deve ser vivido primeiramente sozinho, sem necessariamente isolar-se. E, num segundo momento, fazer com que outras pessoas percebam e compartilhem deste momento. Talvez tenha sido esta possibilidade o que de mais produtivo tivemos nestes encontros. A leitura que cada um trouxe de si mesmo, suas próprias experiências, fez com que nos remetêssemos ao que os sociolingüistas chamam de recursos dos membros1 [1] .

1 [1] O termo recursos de membros é usado pelos sociolingüistas no estudo da Teoria Social do Discurso. O trabalho é desenvolvido a partir da interpretação de um texto e sua relação com o leitor. Entende-se por recurso dos membros, aquilo que o leitor traz 
Com a experiência, vêm, também, os perigos desta prática. Segundo Larrosa, numa conferência proferida durante o I Seminário Internacional de Educação de Campinas (2001), a palavra experiência vem do latim e significa provar, experimentar. Portanto, podemos dizer que experiência é o encontro com algo que se experimenta ou se prova. Ainda, segundo Larrosa, é o momento em que o sujeito se ex-póe a uma travessia determinada, perigosa, estranha. Atravessar que faz com que o objeto da experiência tenha uma existência para o sujeito da experiência. Encontro esse que é irrepetível, intransferível e singular.

O Projeto é entendido como encontro pois, ele nos leva a viver e con-viver com pessoas, pensamentos, vontades, inquietudes... Assim, o encontro tem hora e local prédeterminado para acontecer, exige um tempo para planejamento, estudo prévio, o que nem sempre quer dizer que vai ser cumprido. Então o acontecimento pode ser ao mesmo tempo algo já previamente imaginado ou, uma grande surpresa. E esta surpresa-perplexa permeia a proposta metodológica do projeto $e$, talvez, constitua a possibilidade de propiciar um ambiente escolar mais interessante e privilegie a investigação filosófica coletiva, a qual, por sua vez, venha a estimular um conjunto de práticas atitudinais, intelectuais e sociais.

Atitudinais entendidas como uma prática para exercitar atitudes e disposições adequadas à investigação filosófica como: não aceitar prontamente como óbvias ou evidentes as coisas mas sim, procurar problematizá-las, cultivar a curiosidade epistemológica que sempre leve a novas descobertas. Ou melhor, propor tentativas de desconstruir e re-costruir conceitos.

\section{Alguns destes encontros...}

As experiências vivenciadas no GAN nos deram a oportunidade de observar e questionar o que é pensar filosoficamente. Fizemos de nossas aulas momentos de discussão e reflexão sobre assuntos como o limite, a mãe, a criatividade, a linguagem visual, as diferenças culturais dentre outros temas. Como não podia deixar de acontecer, alguns alunos se

consigo, sua experiência de vida, seus conhecimentos, enfim, sua leitura do próprio mundo (Fairclough, 1989: 141/142). 
mostraram mais interessados nas aulas, outros, de vez em quando atentos, poucos ficaram indiferentes. Algumas atividades proporcionavam a participação da maioria dos alunos, dessa forma ouvíamos aqueles menos participativos.

Levar a filosofia para a escola e fazer dela uma prática, com a participação de todos, professores e alunos, na elaboração das aulas, foi uma experiência democrática de valorização dos saberes distintos. Muitos estudantes se sentiram à vontade para estabelecer conosco uma relação mais estreita e amigável e isso aconteceu a partir do momento em que não assumimos o papel de mestres retentores do saber que ali seria ministrado. Tivemos o prazer de planejar aulas com materiais e assuntos escolhidos por alunos. A vontade de alguns deles de participar das aulas chegou a ponto de um dia, um estudante vir nos pedir quinze minutos para expor um pensamento à turma $e$ assim escutar $e$ repensar o que vinha divagando, o tema era a origem da vida. A sua participação foi bem vinda pelo grupo em geral e fez surgir outros questionamentos existenciais tais como: Deus existe? Como explicar a origem da vida? Para quê a religião? Para onde iremos quando morrermos? E assim foi a aula que criou um clima especialmente tenso ao botar em questão temas tão provocantes envolvendo ciências e religião.

Em uma das aulas, em que utilizamos as fotografias de Sebastião Salgado do livro Exxodo, percebemos que muitos jovens presos a conceitos arraigados e forjados no senso comum, não tentaram ousar novas leituras. Imagens que poderiam gerar discussões sobre diferentes realidades e modos de vida foram deixadas de lado ou, forçosamente adaptadas às suas realidades. Uma das imagens era um garoto negro, com uma bola artesanal, sem blusa, sujo de terra e com um sorriso enorme. A interpretação foi de que era uma criança africana, porque era negra, pobre, suja e com uma bola feita de pano. E era uma criança triste, por ser negra, pobre e suja. A interpretação dada pelos alunos expressa que a lógica ocidental colonialista impera em seus pensamentos e que questionar essa ideologia é difícil quando estamos imersos nela. Mais uma vez vemos a importância do pensar e do questionar o que é natural para nós, filosofar sobre os contextos de vida, conhecer o que é cultura e respeitar as diferenças. 


\section{Pensamentos sobre a "filosofia"...}

\section{Os nossos questionamentos sobre o pensamento filosófico...}

Terminamos alguns encontros com a dúvida de como deveríamos tratar o pensamento filosófico. E... o que diferencia o pensamento filosófico? Quais as estratégias programadas para experienciar o pensamento filosófico? Quem ou o que daria o tom para justificar a possibilidade do pensamento filosófico? Qual a medida utilizada para a garantia do pensamento filosófico? Ou... se deveríamos no acontecendo privilegiar o acontecimento? Questões inerentes, que incomodam e difíceis de serem enfrentadas dentro de uma instituição que traz no seu bojo ranços de conservadorismo, de manutenção e partilha do senso comum. Instituição constituída numa visão utilitarista $e$ que precisa demonstrar resultados aplicáveis num determinado tempo.

Deleuze e Guattari dizem que filosofia é a arte de criar conceitos e citam Nietzsche para mostrar que o pensamento é criação, não vontade de verdade. E como trabalhar com o pensar, numa turma de $8^{a}$ série de escola pública, desmontando o tão caro conceito de verdade na imagem clássica do pensamento? E se pensamento não é vontade de verdade, ainda em Deleuze e Guattari, como abordar o pensamento como pura possibilidade de pensar sem definir um eu pensador? (2000:73).

Tirar do cogito a idéia da verdade cartesiana do existo porque penso, parece constituir uma violência que o homem moderno, desconfiado e num estado de perplexidade, não consegue ainda vislumbrar. E os aparatos institucionais de educação já acenam com uma pálida mudança em nome da diferença, da alteridade e da multiplicidade, mas sempre com o objetivo de tornar iguais os sujeitos de direito, sob a égide da cidadania. E que, talvez, seja oportuno problematizar o discurso atual das escolas que acolhe as diferenças, mas sempre com o intuito de torná-las iguais e partícipes de um estado de direito, para atender sujeitos-cidadão.

Parece-nos que o eu penso ou o em si vem dando lugar a idéia de co-existência, que num primeiro momento pode dar a sensação de pertença, de acolhimento ao outro, ao diferente, ao múltiplo, mas não temos certeza se proporciona e acolhe singularidades. 
Singularidade, aqui, permeia o conceito de acontecimento, de possibilidade, de devir, de movimento e de multiplicidade. Retira a idéia do uno, do fixo, do prévio, do sentido único e, também, do dialético. Singularidade que co-existe com outros corpos, mas não num estado de harmonia ou de ordem, mas de permanente produção. Produção de processos de diferenciação.

Realização de processos de diferenciação que se constitui no entre, nos vãos de um campo vital, no recorte do caos para proporcionar a criação de conceitos, que Deleuze e Guattari chamaram de plano de imanência. Conceitos que não trazem verdades absolutas, mas que, num perene movimento, emergem e submergem numa velocidade infinita. Que não demandam origem e fim, mas sabem que constituem e são constituídos num plano movediço e sem hierarquias, não cabendo visões dualistas de bom/mau, melhor/pior, positivo/negativo, certo/errado.

\section{Uma tentativa de pensamento na prática...}

Para entender um pouco o plano de imanência e sua importância para a criação de conceitos, para o pensamento filosófico e para possibilitar singularidades usamos, de Deleuze e Guattari, a metáfora do horizonte. "Os conceitos são acontecimentos, mas o plano é o horizonte dos acontecimentos, o reservatório ou a reserva de acontecimentos puramente conceituais: não o horizonte relativo que funciona como um limite, muda com um observador e engloba estados de coisas observáveis, mas o horizonte absoluto, independente do observador, e que torna o acontecimento como conceito independente de um estado de coisas visível em que ele se efetuaria." (2000:54)

O horizonte é a possibilidade de pensar o pensamento como movimento. No horizonte relativo o sujeito quanto mais avança, mais se distancia; no horizonte absoluto o

sujeito está nele sempre e já. É o plano de imanência. Os conceitos são intensidades de conveniência ou não do plano de imanência, traçados de uma linha de fuga, não para atender fantasias, sonhos ou projetos, mas encontros. Não para tornar o pensamento, outro, mas devires, que já não é um ou outro, mas que está entre um e outro. Daí, o pensamento ser um movimento infinito, não de fusão, mas de reversibilidade, não de reconhecimento, mas de captura. 
Segundo Deleuze a captura é assimétrica, é evolução a-paralela, é sempre fora e entre. É achar, encontrar, roubar, ao invés de regular, reconhecer e julgar, e que não permite método. É sempre emergência de idéias ou pensamentos, mas sem enquadramentos ou modelos justos. Ou antes, são encontros que geram acontecimentos, acontecimentos que geram experiências. O correr riscos... E... como correr riscos num projeto? Como prescindir de um método.

Sabemos que o próprio projeto reconhece o seu risco como prática e não promete tesouros certos no final do caminho. Mas consideramos uma tentativa audaciosa, porque no momento em que um aceita o outro, como outro, o desacordo é possível.

Vivenciar a filosofia no GAN foi tarefa difícil e inquietante, mas prazerosa. O tempo todo estávamos sendo surpreendidos por estudantes que se mostravam dispostos a debater $e$ entender a filosofia como, segundo Kohan, no texto "Fundamentos à prática da filosofia na escola pública”, uma experiência de pensamento, um movimento do pensar que atravessa a vida de quem a pratica (2000:31). E o projeto pode promover essas experiências de grupo, onde professores e alunos pensem, repensem, escutem e desenvolvam diferentes formas do pensar e onde o pensar filosófico pode vir acontecer. Acreditando nessas coisas... marcamos novos encontros. 


\section{Referências Bibliográficas}

DELEUZE, Gilles, GUATTARI Felix. O que é filosofia. São Paulo: Editora 34,2000. PARNET, Claire. Diálogos. São Paulo: Editora Escuta, 1998.

FOUCAULT, Michel. El yo minimalista y otras conversaciones. Buenos Aires: La Marca,

1996.

FAIRCLOUGH, Norman. Language and power. Londres, Longman: 1989.

LARROSA, Jorge. Seminário Internacional de Educadores de Campinas. 2001 (mimeo).

KOHAN, Walter Omar, LEAL, Bernardina, RIBEIRO, Álvaro (orgs.). Filosofia na escola

Pública. Petrópolis, RJ:2000. 